\title{
DESGASTE FÍSICO E MENTAL DE AUXILIARES DE ENFERMAGEM: UMA ANÁLISE SOB O ENFOQUE \\ GERENCIAL*
}

Moema Miranda de Siqueira**

Fernanda Sue Watanabe***

Adriana Ventola***

Buscando melhor compreender o trabalho em organizações de saúde. Foi realizada uma pesquisa em hospitais gerais contemplando alguns grupos ocupacionais. Supõe-se que a atividade de lidar com dor, sofrimento e morte interfere na organização, gestão, condições de trabalho e que de maneira geral. Expõe os trabalhadores dessas organizações a um desgaste físico e mental intenso. Percebeu-se, no entanto, que tanto as organizações quanto os próprios grupos ocupacionais tem ainda pouca consciência sobre estes problemas, desenvolvendo poucas formas de regulação ou atenuação dos conflitos daí decorrentes. $O$ artigo apresenta uma análise específica sobre o grupo de auxiliares de enfermagem e sugere, a título de conclusivo, algumas medidas que podem melhorar essa situação.

Unitermos: relações de trabalho, processo saúde/trabalho, desgaste no trabalho, condições de trabalho

\section{INTRODUÇÃO}

Existe já razoável grau de consenso em nível nacional e internacional sobre os problemas e estrangulamentos do setor saúde e até mesmo sobre possíveis soluções. No entanto, as dificuldades práticas de se encaminhar e implementar mudanças indispensáveis, principalmente aquelas ligadas ao desempenho dos

\footnotetext{
*Esta pesquisa conta com o apoio financeiro da FAPEMIG e do CNPq

**Professora Titular da Faculdade de Ciências Econômicas da UFMG

***Assistente de Pesquisa e Administradora da UFMG
} 
Recursos Humanos tem constituído um grande desafio para países de diferentes níveis de desenvolvimento. No atual contexto de agravamento da crise econômica, impõe-se a ampliação do entendimento da problemática Recursos Humanos em Saúde, possibilitando a formulação de sugestões mais viáveis.

Com este objetivo, foi realizada uma pesquisa sobre Relações de Trabalho em hospitais gerais ${ }^{\star \star \star \star}$ na qual, adotando-se o enfoque gerencial, foram destacados alguns grupos, entre os quais o de auxiliares de enfermagem. A escolha dos auxiliares de enfermagem justifica-se pelo papel importante que os mesmos desempenham no cuidado direto ao paciente, bem como o número de profissionais desse grupo em relação ao total da equipe de enfermagem e mesmo do hospital como um todo.

Assim, os aspectos da organização do trabalho, da gestão da força de trabalho, das condições de trabalho e das formas de regulação de conflitos desse grupo específico de trabalhadores são úteis para o entendimento do desgaste físico e mental do trabalho em hospitais e para a formulação de sugestões de melhoria.

\section{METODOLOGIA}

A pesquisa foi realizada em seis hospitais gerais no período de 1991-1992, três públicos e três privados, representando uma amostra significativa da rede hospitalar geral de Belo Horizonte - Minas Gerais - Brasil.

O processo de levantamento de dados foi composta de duas etapas. Primeiramente, foram entregues questionários semi-abertos a 74 auxiliares de enfermagem. Após a análise e interpretação dos mesmos foram relacionados os aspectos de maior incidência e significância, para a realização de 24 entrevistas em profundidade, primeiramente gravadas, sendo transcritas para o respectivo mapeamento dos depoimentos. Paralelamente, foram realizadas entrevistas com uma chefia administrativa e uma chefia de enfermagem de cada hospital, além de entrevistas com um representante do sindicato da categoria e um médico do trabalho.

Foi feita uma análise quantitativa de alguns dados numéricos e outra qualitativa, ilustrada com depoimentos, fundamentada em um modelo de Relações de Trabalho especialmente desenvolvido para a pesquisa "Relações de Trabalho em hospitais de Belo Horizonte".

\section{REFERENCIAL TEÓRICO}

A análise do trabalho no interior das organizações concretas, além de considerar condicionantes da sociedade que o afetam de modo especial, como a

\footnotetext{
**** Relações de Trabalho em Hospitais de Belo Horizonte. Pesquisa financiada pela FAPEMIG e CNPq. UFMG, 1993. SIQUEIRA, M.M.; VENTOLA, A.; WATANABE, F.S.; LEITE, A.P.; MORAIS, E.M.; GALIZZI, M.L.; EVORA, A.R.
} 
tecnologia, o mercado de trabalho e o grau de organização sindical de grupos específicos de trabalhadores, pode ser facilitada pela sistematização das relações particulares que aí se desenvolvem para a sua realização. Este enfoque, conhecido como de "Relações de Trabalho" na moderna teoria gerencial, privilegia a organizações do trabalho, a gestão da força de trabalho, as condições de trabalho e as formas de regulação de conflitos. Tais aspectos não são realidades estanques, mas se interpenetram e confundem na prática das organizações, tendo utilidade maior como instrumentos de compreensão e análise (SIQUEIRA, 1991).

Especificamente no que se refere às Condições de Trabalho, o enfoque gerencial incorpora contribuições de outras ciências, permitindo uma abordagem mais holística.

O pensamento clássico da medicina ocupacional entendia a saúde do trabalhador como relacionada apenas ao ambiente físico, na medida em que esse põe o trabalhador em contato com agentes químicos, físicos e biológicos que the causam acidentes e enfermidades. No entanto, reconhece-se hoje que a relação entre saúde e trabalho comporta bases mais amplas.

Nesta perspectiva, o trabalho, como categoria social, está sujeito a múltiplos condicionantes. As condições de trabalho e suas patologias estão estreitamente relacionadas a outras variáveis, como organização do trabalho e refletem valores e regras da sociedade (LAURELL, 1985).

Na mesma linha, PICALUGA (1982) afirma que o desgaste do trabalhador em seu trabalho e condicionado por condições gerais de vida e pelas relações específicas desse trabalho.

Apesar da legislação aceitar a relação entre agentes físicos, químicos e biológicos na produção de riscos e doenças ditas "ocupacionais", existe ainda resistência na aceitação, em quase todos os países, desses outros condicionantes como fator morbigênico (PITTA, 1990).

Um marco importante na abordagem dessa temática foi a introdução da "subjetividade" operária para a definição das condições de trabalho, do desgaste físico e mental dos trabalhadores e da construção de suas estratégias defensivas (DEJOURS, 1980).

Não significa considerar o trabalho, a priori, como fonte de sofrimento. Ao contrário, e através dele que o indivíduo se constitui como sujeito, afirmando sua identidade e seu desejo de ser reconhecido socialmente. O trabalho tem, portanto, virtualmente, um poder estruturante em relação ao equilíbrio psíquico dos indivíduos. No entanto, as relações de trabalho no interior das organizações freqüentemente despojam o trabalhador de sua subjetividade excluindo o sujeito e fazendo do homem uma vítima de seu trabalho (DEJOURS, 1992). Certas regularidades desse confronto do indivíduo com o seu trabalho passam pelo coletivo, sendo então, nessa instância, construída as estratégias defensivas dos trabalhadores. Cada tipo de trabalho apresenta exigências e pressões diferentes, suscitando estratégias de defesa específicas. 
Para a área de saúde, no que se refere à tecnologia do processo de trabalho, o saber e a técnica dos trabalhadores são tão ou mais indispensáveis que os materiais e equipamentos (PITTA, 1990). No entanto, as alterações tecnológicas ocorridas no trabalho em saúde, embora implicando, de um lado, em um processo mais coletivo, na medida em que as tarefas de um grupo profissional dependem de outro, tem tido como conseqüência, por outro lado, uma concentração das atividades reflexivas e de maior autonomia em apenas alguns grupos profissionais, permanecendo uma proporção cada vez maior de trabalhadores com atividades meramente rotineiras e padronizadas. A execução automatizada de prescrições, no caso dos $\mathrm{AE}$, é um exemplo desta característica.

Além disso, o lidar com doença e morte exige cuidado prévio na escolha da ocupação e, no cotidiano, o desenvolvimento de estratégias defensivas contra a grande ansiedade gerada pelo próprio trabalho, que pode ser atenuada ou exacerbada pelas Relações de Trabalho.

Segundo MENZIES (1970. apud PITTA, 1990), as principais estratégias defensivas dos trabalhadores hospitalares são:

- fragmentação da relação técnico/paciente: se a relação for muito íntima, o profissional se tomará mais passível de angústia. Assim, o parcelamento da tarefa resulta em redução do tempo de contato com os pacientes;

- despersonalização e negação da importância do indivíduo (todo paciente é igual), que se traduzem no uso de uniformes;

- distanciamento e negação de sentimentos através do controle dos mesmos;

- eliminação de decisões por meio de ritual de desempenho de tarefas, buscando rotinas e padronizações. O dispêndio de tempo e energia para padronizar cuidados funciona como ritual de postergação e controle de decisões que deverão ser tomadas frente a demandas de doentes;

- redução do peso da responsabilidade em função do parcelamento, fragmentação e supervisão de tarefas.

TONNEAU (1991) aponta como fatores de penosidade para os trabalhadores hospitalares: a) carga mental, decorrente de memorização complexa, parcelamento do trabalho e esclarecimentos insuficientes; b) carga psíquica, decorrente de pressão da concentração de trabalho, pressão das mudanças nas condições de risco do paciente e do confronto com o sofrimento.

$\mathrm{Na}$ Europa, nos últimos anos, os esforços para melhorar as condições de trabalho em saúde concentraram-se na redução da jornada de trabalho, melhora dos materiais e formação para integração (POINSIGNON, 1991). A luta sindical da categoria entre nós encontra-se ainda mais atrasada, sendo que apenas os hospitais públicos conseguiram redução de jornada e os outros itens são muito pouco considerados.

Em resumo, parece consensual que qualquer análise que se pretenda realizar sobre desgaste no trabalho em saúde supõe incorporação de variáveis de diferentes natureza e abrangência.

\section{RESULTADOS}

O quadro que se segue resume as principais características do trabalho dos Auxiliares de Enfermagem entrevistados nos hospitais da amostra (Quadro 1). 


\section{QUADRO 1 - QUADRO RESUMO DE VARIÁVEIS DE RELAÇÕES DE TRABALHO EM HOSPITAIS GERAIS DE BELO HORIZONTE - 1991/1992}

\section{AUXILIARES DE ENFERMAGEM}

\begin{tabular}{|c|c|c|}
\hline $\begin{array}{l}\text { VARIÁVEIS } \\
\text { MICROSSOCIAIS }\end{array}$ & CARACTERÍSTICAS & $\begin{array}{c}\text { INFLUÊNCIA NAS RELAÇÕES } \\
\text { DE TRABALHO }\end{array}$ \\
\hline $\begin{array}{l}\text { ORGANIZAÇÃO DO } \\
\text { TRABALHO }\end{array}$ & $\begin{array}{l}\text { - tarefas rotineiras e repetitivas } \\
\text { - parcelamento de tarefas e baixa } \\
\text { rotatividade de tarefas } \\
\text { - supervisão rígida de horários e } \\
\text { faltas } \\
\text { - normas definidas na lei de } \\
\text { regulamentação da profissão } \\
\text { - submissão ao trabalho médico } \\
\text { - número de pessoal reduzido } \\
\text { (percepção) }\end{array}$ & $\begin{array}{l}\text { - trabalho repetitivo atua no } \\
\text { sentido da monotonia, pouca } \\
\text { criatividade e desmotivação } \\
\text { - dependência dos colegas } \\
\text { - especialização } \\
\text { - controle maior sobre o } \\
\text { empregado } \\
\text { - inexistência de treinamento na } \\
\text { organização } \\
\text { - nenhuma autonomia e poder de } \\
\text { decisão } \\
\text { - rapidez nas tarefas apesar da } \\
\text { exigência de precisão }\end{array}$ \\
\hline $\begin{array}{l}\text { GESTÃO DA FORÇA } \\
\text { DE TRABALHO }\end{array}$ & $\begin{array}{l}\text { - não há treinamento } \\
\text { - inexistência de política de } \\
\text { benefícios } \\
\text { - inexistência de plano de carreira }\end{array}$ & $\begin{array}{l}\text { - valorização da experiência } \\
\text { anterior } \\
\text { - desmotivação e insatisfação }\end{array}$ \\
\hline $\begin{array}{l}\text { CONDIÇÕES DE } \\
\text { TRABALHO E SAÚDE } \\
\text { DO TRABALHADOR }\end{array}$ & $\begin{array}{l}\text { - ambiente físico precário } \\
\text { - falta de materiais, equipamentos } \\
\text { e medicamentos } \\
\text { - grande esforço físico } \\
\text { - tratar com o sofrimento alheio } \\
\text { - baixos salários } \\
\text { - não têm direito a nenhum plano } \\
\text { especial de assistência médica }\end{array}$ & $\begin{array}{l}\text { - dificulta realização do trabalho, } \\
\text { aumenta a insatisfação } \\
\text { - tensão e cansaço constante, } \\
\text { dores lombares } \\
\text { - grande número de faltas e } \\
\text { licenças } \\
\text { - desgaste emocional } \\
\text { - sentem-se pouco valorizados } \\
\text { pela organização } \\
\text { - sentem-se explorados }\end{array}$ \\
\hline $\begin{array}{l}\text { FORMAS DE } \\
\text { REGULAÇÃO DE } \\
\text { CONFLITOS }\end{array}$ & $\begin{array}{l}\text { - participam de decisões somente } \\
\text { ligadas ao próprio trabalho } \\
-\quad \text { inexistência de formas } \\
\text { institucionalizadas de regulação de } \\
\text { conflitos }\end{array}$ & $\begin{array}{l}\text { - principais reivindicações: salário } \\
\text { e condições de trabalho } \\
\text { - profissão ligada a valores } \\
\text { religiosos (conformismo e } \\
\text { submissão) } \\
\text { - vocação (trabalho por amor) - } \\
\text { satisfação com a profissão }\end{array}$ \\
\hline
\end{tabular}


A análise qualitativa dos depoimentos reforça as características apresentadas nos quadros anteriores. Para este artigo, procurou-se destacar aquelas relativas ao desgaste físico e mental dos Auxiliares de Enfermagem.

O trabalho humano pode significar realização, satisfação, riqueza, bens materiais e serviços úteis à sociedade. Por outro lado, pode também significar exploração, sofrimento, doença e morte (SILVA, 1987).

Para os auxiliares de enfermagem ( $A E$ ) entrevistados, nem sempre esses dois aspectos do trabalho estão nitidamente perceptíveis. Inicialmente, os AE estão expostos a numerosos riscos à sua saúde física no curso de seu trabalho.

No grupo de agentes biológicos estão os causadores de doenças infecciosas e parasitárias, as quais, para os trabalhadores de enfermagem são, principalmente, tuberculose, hepatite, rubéola, herpes, meningite e escabiose. Em um dos hospitais pesquisados, $60 \%$ dos entrevistados acham que contraíram diversas doenças no hospital, como hepatite $B$, caxumba, rubéola, herpes zoster, psoríase etc.

"Eu mesma tive, eu com as minhas colegas. Coisa comum, mas que a gente acha que pode complicar. Foi psoríase. (...) Foi pega de paciente justamente por falta de material de segurança e falta de supervisão mais cuidadosa. Nós questionamos também que precisava ser isolado. (...) Mas enquanto o paciente não contaminou ' $n$ ' pessoas, inclusive colegas de leito, e outros da área em volta, aliás, pra resumir, quase a ala toda, eles não tomaram providências. Quando o negócio já estava virando briga foi que chamaram o médico e ele mandou isolar o paciente, quando já tinha contaminado tudo. Deu quase uma epidemia. Chegou a sair da nossa ala. Nós tivemos acompanhante de paciente que saiu daqui com a doença". (Depoimento de AE - HO5)

O grupo de agentes químicos constitui-se de gases e vapores anestésicos presentes nas salas de cirurgia; gases e vapores esterilizantes; desinfetantes e medicamentos que podem provocar alergias, sinusite e dermatoses; exposição a raio-x e outras radiações ionizantes. Em um dos hospitais da nossa amostra, um auxiliar de enfermagem se queixou de que apresenta os mesmos sintomas de pacientes submetidos à quimioterapia: secura na boca, coceira e queda de cabelos. Para evitar tais problemas, as atividades deveriam ser realizadas utilizando-se equipamentos de proteção individual, como luvas e câmaras especiais.

No grupo de agentes físicos constam as rampas ausentes ou inadequadas e ausência ou insuficiência de elevadores que provocam quedas, escorregões e cansaço; agulhas, vidros e outros materiais que proporcionaram cortes e perfurações; macas e cadeiras inadequadas para transporte e carregamento de pacientes pesados; posições incômodas que causam dores lombares e varizes.

Por fim, os riscos mentais e emocionais, que estão relacionados principalmente ao próprio conteúdo do trabalho, isto é, a atividade de lidar com a dor, o sofrimento e a morte. Na pesquisa realizada, pode-se verificar que as atividades por elas consideradas mais desagradáveis são justamente aquelas mais diretamente ligadas a quadros terminais ou mais dolorosos, como o tratamento de queimados, o controle de sinais vitais em CTI, a 
quimioterapia e a preparação de mortos.

"Preparo de morte. Pra mim é uma coisa muito penosa pra fazer. As outras eu não reclamo: limpar um paciente vomitado, ou defecado ou sujo, aquela coisa toda. Até que não é problema. Pra mim, problema maior, doloroso mesmo e prepararão de óbito". (Depoimento de AE - HO5)

Por outro lado, as tarefas consideradas mais gratificantes são os pequenos tratamentos, curativos leves, trabalho realizado na maternidade e no berçário.

"O meu trabalho até me alegra, pois não lido com pacientes internados, e sim com gestantes e crianças, que são super saudáveis". (Depoimento de AE - HO5)

Para lidar com tanto sofrimento, o trabalhador de enfermagem tem que aprender a utilizar estratégias defensivas controlando e negando seus sentimentos, distanciando-se do paciente. No entanto, muitos deles não conseguem e acabam colocando-se no lugar do paciente, sofrendo junto com ele.

"Fico deprimida, muito deprimida. Fico penalizada, porém a gente chega a um certo ponto que a gente acostuma. Não é bem que acostuma, porque é a minha função. Eu tenho que fazer aquilo e faço o que posso. Se puder, tudo bem; se não puder...". (Depoimento de $\mathrm{AE}$ - HO5)

"Eu sou uma pessoa mais fria nesse sentido. Eu tenho... em termos de profissão eu nunca me envolvi assim diretamente. (...) uma vez, quando eu estava fazendo estagio, fui levar um paciente no chuveiro e ele morreu. Aquilo me deixou um pouco abalado. Mas depois, acho que aquilo me deu oportunidade de dar um chega pra lá". (Depoimento de AE HO5)

Outros relatos encontrados na pesquisa também são expressivos:

"Existe o lado profissional. Anteriormente eu não sentia. Mas hoje, como eu estou cansada da área de saúde, realmente tem me deprimido". (Depoimento de AE - HO5)

"Chega um período que a gente vai ficando com um pouco de neurose. Porque tudo que acontece com o paciente pode acontecer com você também. Então você passa a ficar se colocando no lugar dele". (Depoimento de AE - HO5)

No campo psíquico/emocional, os AE identificam ainda como fontes de sofrimento o trabalho junto a pacientes "difíceis", que reclamam não só do atendimento prestado por eles como também das condições gerais do hospital, sobre as quais o trabalhador não tem autonomia.

"Muitas vezes o paciente questionava o nosso trabalho, mas automaticamente o nosso trabalho era feito daquela maneira por falta de condições técnicas. Ele reclama da pessoa que está diretamente ligada com ele. A primeira pessoa que ele vê na reta ele descarrega, e com toda razão. E a maioria das reclamações, a gente vai analisar, é falta de condições técnicas e humanas, e caso de excesso de trabalho". (Depoimento de AE - HO5) 
"Aqui dentro eles reclamam. Falam com a gente. Não falam diretamente com a administração. (...) tem que reclamar com a administração, porque a gente é simples funcionário. Eles reclamam que não tem conforto, que tá faltando isso, faltando aquilo". (Depoimento de AE - H17)

Outro fator que provoca desgaste é a rivalidade inter. e intra-grupos. Os pacientes mais graves deveriam ser cuidados pela enfermeira de nível universitário. Os técnicos e auxiliares tem quase a mesma função, que é a de assumir a medicação e o cuidado dos pacientes menos graves, cabendo aos atendentes as atividades mais simples. Na prática, as tarefas se confundem, sendo freqüentes as queixas dos auxiliares de que os enfermeiros não assumem os pacientes mais graves e que ficam só com serviços "burocráticos". Além disso, para o paciente, qualquer trabalhador de enfermagem é considerado "enfermeiro", independente de sua titulação. Desta forma, tornam-se pouco eficazes as estratégias defensivas contra o sofrimento, de fragmentação e parcelamento das tarefas, reduzindo o tempo de contato do profissional com o paciente e o peso de responsabilidade, resultando freqüentemente em maior carga sofrimento para os $A E$. As chefias consideram essas rivalidades corriqueiras, mas os grupos acham que há incompatibilidade entre carga de trabalho e salários.

"Rivalidade são percebidas entre o pessoal da internação e da urgência. Uns acham que os outros trabalham menos; esta rivalidade e percebida inclusive entre os médicos". (Depoimento de Chefia)

"Existe rivalidade entre pessoal de limpeza, cozinha e auxiliar de enfermagem, atendente; um pequeno ciúme, um acha que trabalha mais e ganha menos que o outro, essas pequenas coisas". (Depoimento de Chefia)

Em relação à gestão da força de trabalho, merecem destaque o controle rígido de horário e as sanções ao absenteísmo, que são fontes de muita reclamação e insatisfação.

Os baixos salários da categoria (em nenhum dos hospitais pesquisados ultrapassavam a dois salários mínimos em junho/92) também são fonte de grande insatisfação e revelam a própria desvalorização destes profissionais pelos hospitais.

Um fator condicionante para a baixa remuneração e desvalorização do pessoal de enfermagem está ligado a própria evolução histórica do trabalho em enfermagem, relacionado aos valores cristãos de fraternidade e caridade, como forma de salvação da alma. Atribuemse os primeiros serviços de enfermagem a cristãos que desejavam exercitar sua caridade, proporcionando refugio aos enfermos pobres. A despeito de progressiva profissionalização do serviço de enfermagem, sua imagem persistiu vinculada a valores como bondade e humanismo, refreando o nível reivindicatório da categoria.

Os auxiliares de enfermagem que estão sujeitos ao trabalho noturno, devido aos ritmos biológicos não respeitados, podem sofrer de "patologia do trabalhador noturno". A incidência dessa patologia está sujeita a muitas particularidades, às quais se deve estar alerta, tais como: 
“a) transcurso de certo tempo antes que as conseqüências, algumas delas duradouras, se manifestem, o que acentua a importância de se adotar nos estudos todas as precauções metodológicas necessárias;

b) existência de efeitos indiretos, como os da insuficiência e dos transtornos do sono (efeito direto) sobre os transtornos nervosos ou digestivos (efeito indireto);

c) grande diversidade de reações de cada indivíduo segundo sua situação familiar, econômica e social, configurando uma tipologia do trabalhador em turnos". (CARPENTIER, CAZAMIAN, 1977. apud SILVA, 1987)

Retomando-se o conceito adotado no presente estudo, pode-se afirmar que o desgaste no trabalho dos AE é condicionado pelas Relações de Trabalho vigentes no hospital (nível microssocial), destacando-se o ritmo e a carga de trabalho; o grau de autoritarismo das chefias; as fracas possibilidades de carreira e ascensão profissional; a inexistência de formas de participação. Embora o trabalho dos $A B$ em hospitais não possa ser caracterizado como rotineiro, ele apresenta alguns elementos (atenção, velocidade e precisão) que geram sofrimento.

A análise das formas de regulação de conflitos encontradas reforça a visão um tanto "pessimista" das relações de trabalho dos auxiliares de enfermagem. O nível de organização e reivindicação e muito baixo, fazendo com que os dirigentes não sintam necessidade de usar qualquer estratégia de regulação de conflitos nem mecanismos formais de integração.

Segundo PITTA (1990), o mesmo trabalho que produz sofrimento também e capaz de produzir satisfação e prazer, através de mecanismos sublimatórios, quando as tarefas são "socialmente valorizadas". No entanto, a maioria dos Auxiliares não se sente valorizada nos hospitais, percepção esta relacionada aos baixos salários e a falta de incentivos e elogios.

Em relação à sociedade em geral, alguns se sentem mais valorizados, lembrando que as pessoas os elogiam por sua dedicação e abnegação a um trabalho tão humano. Outros, no entanto, acham que a profissão não é valorizada em lugar nenhum, e que as pessoas só se lembram deles quando precisam de sua ajuda.

"Eu acho que o trabalho de enfermagem não é valorizado, nem aqui, nem em lugar nenhum. Nem fora do hospital, ninguém tem consciência. Até na minha família mesmo, tem certo receio de enfermagem. Ganha pouco, não tem valor nenhum. E quem dá valor, dá valor só pro lado sentimental, que é amor, aquele negócio. Aquele discurso de cem anos atrás". (Depoimento de AB - HO5)

"Eu acho que ninguém hoje em dia valoriza enfermagem. Ela deixou de ter algum valor pra alguém. Eu acho que ela só tem valor quando a pessoa precisa dela. Se você tiver internado no hospital, precisando da enfermagem, aí pra você ela passa a ter valor". (Depoimento de AE - HO5)

O que se detecta, então, é que o prazer que o trabalho poderia proporcionar ao Auxiliar seria a sensação de poder de ajudar a salvar vidas (já que o poder de salvar e do médico), ajudar a curar pessoas, oferecendo saúde e bem-estar. Se por um lado este "poder" 
acarreta uma enorme responsabilidade para o trabalhador, já que qualquer erro pode ser fatal, por outro lado ele Ihe confere a sensação de ser alguém especial, dotado de um dom divino.

Os riscos e perigos inerentes às tarefas do auxiliar de enfermagem são exacerbados ainda por outras variáveis sociais, identificadas nas entrevistas, tais como:

a) más condições gerais de vida, como as da maioria dos trabalhadores brasileiros: baixos salários, residências distantes dos locais de trabalho, translado em veículos lotados, alimentação deficiente etc.;

b) perfil de gênero da categoria: $90 \%$ dos trabalhadores são do sexo feminino, submetidos a uma árdua e extenuante dupla jornada: no lar e nos hospitais;

c) grau de instrução relativamente baixo e pouco conhecimento dos fatores de risco e métodos de prevenção, além de pouca tradição em reivindicar e se organizar;

d) precárias condições do ambiente físico do trabalho: iluminação, ventilação e instalações insuficientes; ausência de vestiários adequados; hospitais localizados em áreas onde o nível de ruído e muito elevado;

e) precárias condições para a realização do trabalho: não fornecimento de uniforme para os trabalhadores; falta de equipamentos ou precariedade de materiais de trabalho;

f) atenção médica insuficiente: o próprio hospital não realiza exames médicos para o grupo e nota-se ausência de medidas preventivas e até mesmo curativas;

g) sobrecarga de trabalho: equipes reduzidas.

Somam-se a estes problemas políticas de recursos humanos legalistas (paga-se o mínimo exigido por lei em termos de benefícios e adicionais de insalubridade) e atrasadas (ausência de profissionais de Recursos Humanos nos hospitais, processo de seleção pouco rigoroso, ausência de treinamento e possibilidade de carreira), e trabalhadores submetidos a relações autoritárias/coercitivas e/ou paternalistas com as chefias.

\section{CONCLUSÕES}

A situação tão complexa constatada para o trabalho do $A E$ não pode ser mudada imediatamente, mas um mínimo pode ser assegurado aos trabalhadores, como a implementação das medidas preconizadas pela OIT (MEDIDAS DE PROTEÇÃO; OIT, CONVENÇÃO 149, RECOMENDAÇÕES 157):

- adaptar leis e regulamentos para a saúde ocupacional a natureza especial do trabalho de enfermagem e ao ambiente no qual ele se realiza e aumentar a proteção disposta por eles;

- estabelecer serviços de saúde ocupacional para o pessoal de enfermagem; 
- tomar todas as medidas apropriadas para prevenir, reduzir e/ou eliminar riscos à saúde ou segurança do pessoal de enfermagem;

- realizar exames médicos periódicos ou implantar o sistema de anotações de reações ou sintomas do próprio pessoal de enfermagem em intervalos regulares durante seu serviço. Devem ser assegurados objetividade e segredo (discrição) dos arquivos médicos, os exames sendo feitos preferencialmente por médicos com os quais a pessoa examinada não tenha um relacionamento profissional próximo;

- promover estudos e coleta de dados para determinar riscos especiais aos quais o pessoal de enfermagem possa ser exposto, de modo que esses riscos sejam prevenidos, removidos ou compensados;

- providenciar roupas de proteção e medidas de imunização;

- implantar jornadas reduzidas, horas de descanso mais freqüentes e férias mais longas;

- garantir compensações financeiras para o pessoal de enfermagem que trabalha em áreas que envolvem maior risco;

- zelar para que mulheres grávidas e pais de crianças pequenas sejam alocados em trabalhos que não envolvam riscos à sua saúde ou de seus filhos, sem qualquer prejuízo de sua situação funcional;

- as corporações deste grupo profissional devem ser chamadas a colaborar com as autoridades competentes no sentido de assegurar medidas efetivas de proteção à saúde e seguridade do pessoal de enfermagem.

\section{MENTAL AND PHYSICAL STRESS OF AUXILIARY NURSES: ANALYSIS OF MANAGEMENT}

Seeking a better understanding of job stress, auxiliary nurses were evaluated in General Hospitals Belo Horizonte. The emotional stress which accompanies auxiliary nurses caring for the sick and easing physical and mental suffering affects their own mental state and physical health. Elements that cause suffering and diseases can be attenuated or intensified depending on labor relations. However, organizations have not been concerned about working conditions. This paper suggests some protective safety and health measures that can improve labor relations and consequently reduce the suffering of working in hospitals.

UNITERMS: labor relations, the process health/work, job stress, working conditions 


\section{DESGASTE FÍSICO Y MENTAL DE AUXILIARES DE ENFERMERÍA: UN ANÁLISIS BAJO EL ENFOQUE GERENCIAL}

Buscando comprender mejor el trabajo en organizaciones salud, fue realizada una investigación en hospitales generales contemplando algunos grupos ocupacionales. Se supone que una actividad ligada a dolor, sufrimiento y muerte interfiere en la organización, gestión, condiciones de trabajo y que de manera general, expone a los trabajadores de esas organizaciones a un desgaste físico y mental intenso. Se notó también, que tanto las organizaciones como los propios grupos ocupacionales aún tienen escasa conciencia sobre estos problemas, desenvolviendo pocas formas de regulación o atenuación de los conflictos decorrentes. El artículo presenta un análisis específico sobre el grupo de auxiliares de enfermería y sugiere, a título de conclusión medidas que pueden mejorar esa situación.

UNITERMOS: relaciones de trabajo, proceso salud/trabajo, desgaste en el trabajo, condiciones de trabajo

\section{REFERÊNCIAS BIBLIOGRÁFICAS}

01. CARPENTIER, J.; CAZAMIAN, D. Le travail du nuit. Geneva: Bureau International du Travail, 1977. apud SILVA, Edith S. Saúde mental e trabalho. In: TUNDIS, S.; COSTA, N.R. (org.). Cidadania e loucura: políticas de saúde mental no Brasil. Petrópolis: Vozes, 1987. p. 217-288.

02. DEJOURS, C. A loucura do trabalho: estudo da psicopatologia do trabalho. São Paulo: Oboré, 1987.

03. Travail: usure mentale. Essai de psychopathologie du travail. Paris: Centurion, 1980.

04. et al. Psychopathologie du travail. Paris: Entreprise Moderne d'Edition/CNRS, 1985.

05. DIAS, E.C. Evolução e aspectos atuais da saúde do trabalhador no Brasil. Bol Sanit Panam, v. 115, n. 3, p. 202-14, 1993.

06. LAURELL, A. C. Saúde e trabalho: os enfoques teóricos. In: NUNES, Everardo D. (org.). As ciências sociais em saúde na América Latina: tendência e perspectivas. Brasília: OPAS, 1985.

07. MENDES, R. Doutrina e política da integração da saúde ocupacional no setor saúde: contribuição para a definição de uma política. São Paulo, p. 348. Tese (LivreDocência) - Faculdade de Saúde Pública -USP, 1986. 
08. MENZIES, I. The functioning of organizations as social systems of defense against anxieties. Institute of human relations, 1970. apud PITTA, Hospital: dor e morte como ofício. São Paulo: HUCITEC, 1990.

09. ORGANIZAÇÃO MUNDIAL DA SAÚDE. Condições de trabalho. Genebra, 1985. (Informe Técnico)

10. PICALUGA, I. F. Saúde e trabalho. In: IBASE. Saúde e trabalho no Brasil. Petrópolis: Vozes, 1982. p. 37-42.

11. PITTA, A. M. F .de. Hospital: dor e morte como ofício. São Paulo: HUCITEC, 1990.

12. POINSIGNON, H. Changer le travail à I'hôpital. [s.I.]: ANACT, 1991.

13. SILVA, E. S. Saúde mental e trabalho. In: TUNDIS, S.A.; COSTA, N.R. ( orgs .) .Cidadania e loucura: políticas de saúde mental no Brasil. Petrópolis : Vozes,1987. p.217-88.

14. SILVA, E. M.; GOMES, E.L.R. Enfermagem: realidade e perspectiva na assistência e no gerenciamento. Rev. Latino-Am. Enfermagem. Ribeirão Preto, v.l, n.I, p. 59-64, janeiro 1993.

15. SIQUEIRA, M. M. de. Relações de trabalho em hospital público e privado de Belo Horizonte: análise dos grupos de residentes, pessoal de limpeza e auxiliares de enfermagem. Belo Horizonte. Tese (Titular) -UFMG, 1991.

16. TONNEAU, D. Les conditions de travail à I'hôpital, un enjeu vital. [s.I.]: ANACT,1991. 